\title{
CENTRAL BANKING, PROTECTIONISM AND GLOBALIZATION
}

\author{
FRENKEL, Jacob A.
}

The recent global financial crisis has resulted in a new creative set of economic policies. The justification for the unconventional policy response was based on the implicit assumption that the departure from the norms of macroeconomic policies would be temporary. This detour has lasted longer than expected. Now that the process of normalization has started in the United States and is likely to be followed (albeit in some delay) in Europe, it would be important for policy makers to emphasize that the unconventional set of economic policies were just a detour from the longstanding convention rather than representing a new paradigm. The experience of the crisis and the post-crises years should be recorded in history as reflecting a period during which new and important policy chapters were drafted. These chapters should be added to the corpus of knowledge of macroeconomic theory and policy. The new chapters contain important lessons that should definitely not be forgotten once the crisis is over. They should be added to, but not replace, the old textbooks.

Keywords: financial crises, fiscal policy, globalization, GDP growth, central banking, international trade

JEL classification indices: E5, E62, F4, 901

Frenkel, Jacob A., Chairman of JP Morgan Chase International, Chairman of the Board of Trustees of the Group of Thirty (G30), Former Governor of Bank of Israel between 1991-2000.

E-mail: jacob.frenkel@jpmorgan.com 
I am very pleased to contribute to this Special Issue of Acta Oeconomica in honor of Professor Grzegorz W. Kolodko on the occasion of his $70^{\text {th }}$ birthday. Professor Kolodko is one of the most prolific scholars. Since the mid-1980s, he has published scholarly papers covering a wide range of topics. These include among others, key issues in economic policies such as: fiscal policy, inflation, stabilization, market reforms, and economic growth. He also contributed to our understanding of globalization - its merits and its challenges -, as well as critical aspects of society and comparative economics. His work has also illuminated important international issues such as: the growth of the Chinese economy, the eurozone crisis, Brexit, and the like. In view of the extraordinary scope and broad reach of Professor Kolodko's research interest, it is difficult to focus on a specific topic that does justice to the breadth of his contributions. In my own paper below, I will touch on some of the issues that have been the subject of Professor Kolodko's writings. I will also pay special attention to key economic policy issues thereby, recognizing the fact that, in addition to Professor Kolodko's contributions to economic research (especially through his leadership of the think tank TIGER (Transformation, Integration, Globalization, and Economic Research), he has also been engaged in economic policy making as Finance Minister of Poland.

This year marks the $10^{\text {th }}$ anniversary of the eruption of the global financial crisis of 2008-2009. It provides a good opportunity for reflections on the recent evolution of central banking theory and practice, as well as on the challenges for globalization, on the emergence of protectionism and on the growth of populism. This brief paper offers few reflections on each.

\section{CENTRAL BANKING}

\subsection{Basic principles}

Over the past decades central banking theory and practice evolved. The economic system, the nature of markets and the structure of economic policies, have changed and have brought about fundamental changes in central bank structures and policies. The mandate of central banks has been modified, the policy instruments have evolved, and the degrees of accountability and transparency have risen. These developments resulted in the current state of affairs in which central banks have become "the only game in town". While this "distinction" is somewhat flattering, it is neither desirable nor sustainable.

A superficial observation of central bank policies today, in comparison with its policies a decade or two ago, may yield the conclusion that at the present we are in a fundamentally different universe than we were in the past. Based on 
this superficial observation one may reach the conclusion that the "new world" requires a fundamentally new approach to central banking, that old concepts are obsolete, that we can throw the old textbooks away and replace them by the new ones. I strongly believe that this would be the wrong conclusion. Even though the economic system has evolved, the basic premises and principles of central banking and the benefits from globalization and open markets, which have been established on the basis of many decades of experience, remain robust, useful, and relevant.

Notwithstanding the fact that the economic circumstances and the legal frameworks differ across countries and have changed over time, the general principles of central banking remain valid and intact. They include a specification of the mandate of the central bank, with a typical focus on the attainment of price stability and financial stability, a medium term perspective, independence from short-term political pressures, autonomy in executing the mandate, responsibility for the smooth operation of the payments system, accountability and, in extreme cases, playing the role of the "lender of last resort". Modern central banking requires that the formal authority of the central bank is specified and protected by an explicit central bank law. Specifically, the recognition that countries with strong central banks exhibit on average a better economic performance than those with weak central banks, have resulted in a convergence of views about the role of central banks in a modern society.

The development of capital markets and the growing integration among such markets have introduced new characteristics to central banking. They resulted in an increased interdependence among economies, thereby increasing attention to international policy coordination and cooperation. In contrast with the relatively slow adjustments in the markets for goods and labor, capital markets adjust very quickly. Changes in capital markets reflect not only current policy actions, but also expected policy actions. As a result, the roles of reputation, consistency, and credibility have become extremely important. The growing importance of capital markets and the expanded roles of banks and the financial sector, have contributed immensely to the performance of the economy but, at the same time, have also increased its degree of vulnerability. Thereby, the functions of supervision and regulation of the financial industry have become a critical factor.

\subsection{The global financial crisis}

The Asian economic crisis and the Russian default which occurred during 19971998, served as a wake-up call and illustrated vividly the importance of capital markets and the critical role that financial stability (and instability) play. How- 
ever, developments during the subsequent decade have revealed that the lessons from the experience of the late 1990s (especially following the Asian crisis and the Russian default), have not been fully learned. Many economies (especially among the industrial countries) have neglected to apply appropriate risk management to their macroeconomic and financial conduct. An exceedingly rapid rise in debt and leverage and a mispricing of risk have increased the vulnerability of the economic system and have ultimately resulted in the financial crisis of 2008-2009. In 2009 the crises brought the world economy to a halt, global growth vanished and the level of output in the industrial countries shrunk by 3.4 percent (Figures 1-2).

The results of this crisis, which erupted as a "perfect storm", are still with us. They have resulted from poor risk management, the failure of bank supervision, the lack of enforcement of the regulatory framework, the deficiencies of the regulatory system itself, the vulnerability that arises from fiscal laxity and excess leverage, from the distortions that arise from lack of flexibility of the economic system, and the like.

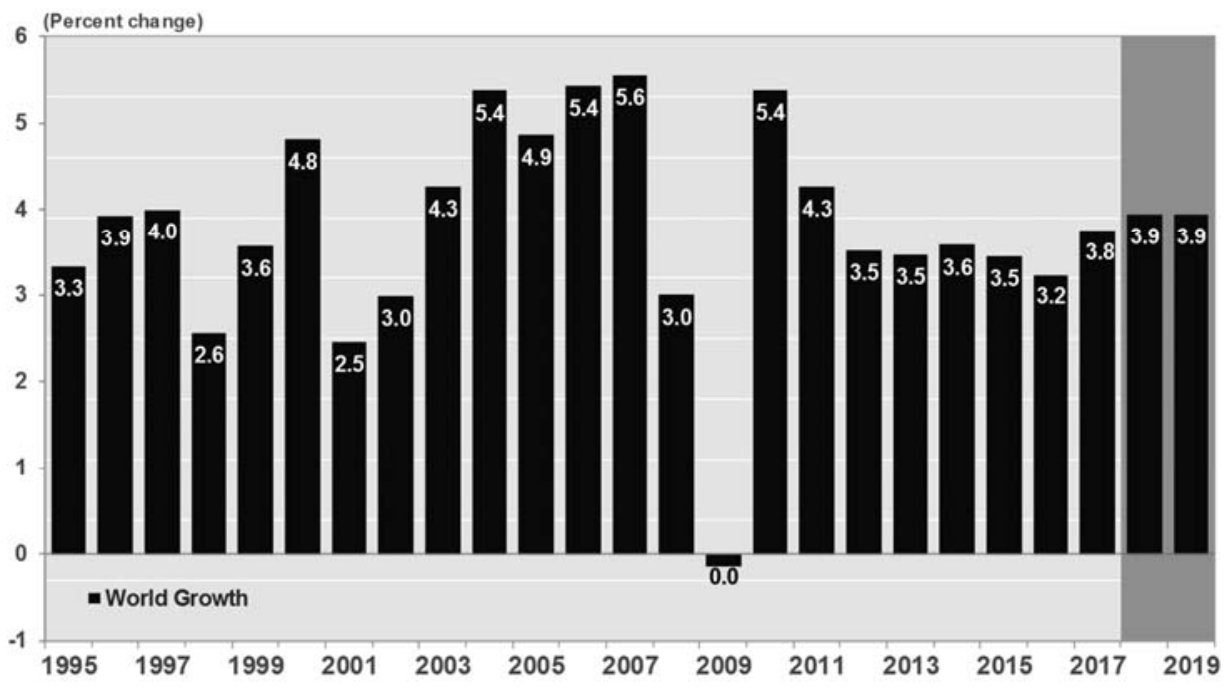

Figure 1. Global GDP growth

Source: Bloomberg Market Data, Last observation: 2 Oct, 2018. 


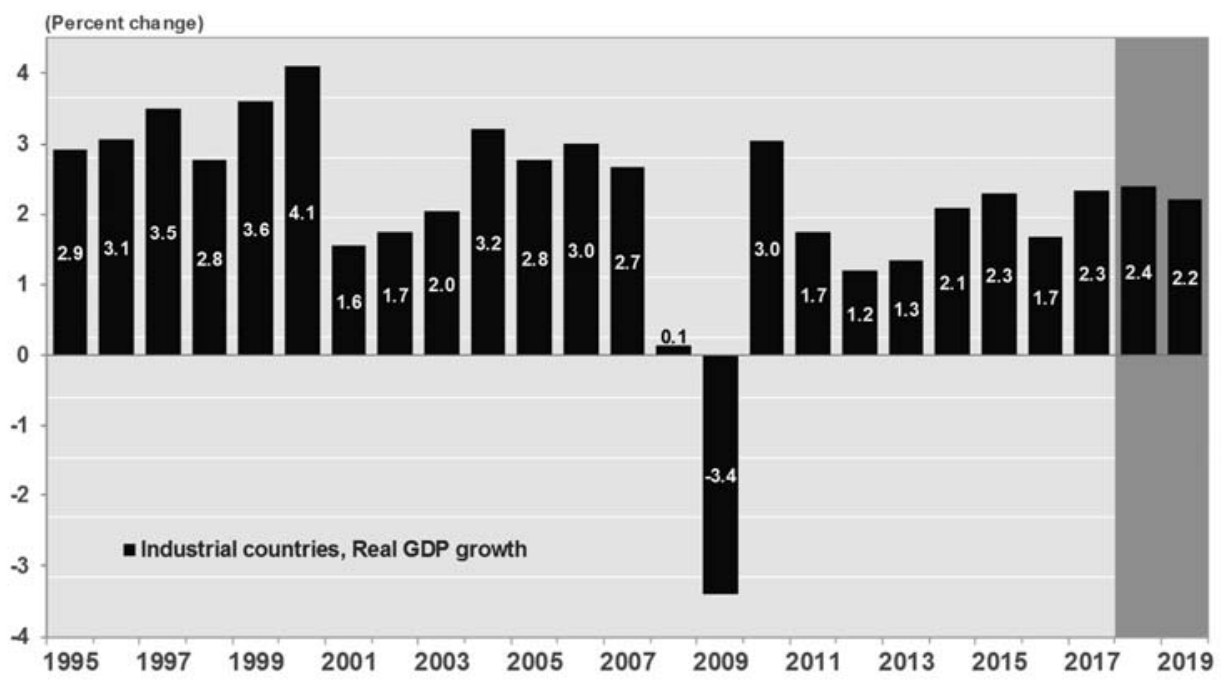

Figure 2. Industrial countries, GDP growth

Source: IMF, last update Jul 16 2018, WEO (2018, 2019 Forecast).

\subsection{Unconventional policies}

In order to avoid a complete meltdown following the outbreak of the 2008-2009 financial crisis, governments in most countries have increased dramatically their budget deficits (fueling further the excessive levels of debt) and central banks all over the world have lowered interest rates to unprecedented low levels (Figure 3).

Thereby, conventional monetary policies reached their limit. Since the economic recovery has not yet been in sight, central banks needed to resort to unconventional measures. The size of the balance sheets of the central banks has expanded at a very rapid rate and the composition of assets in the central bank's balance sheet has also changed dramatically. Instead of holding safe and highly liquid short-term government treasury bills, most of the central banks have accumulated a wide range of lower-quality and less liquid securities such as mortgage-based securities and the like. Clearly, unconventional challenges needed to be met by unconventional measures. Since the various economies suffered from a "balance sheet shock" it was understood that the period of adjustment would not be short. However, in retrospect, it is fair to say that very few policy makers and market participants expected the period during which central banks would have had to resort to unconventional measures, to be so long. The lengthy period during which the unconventional policies have been in place has created the 


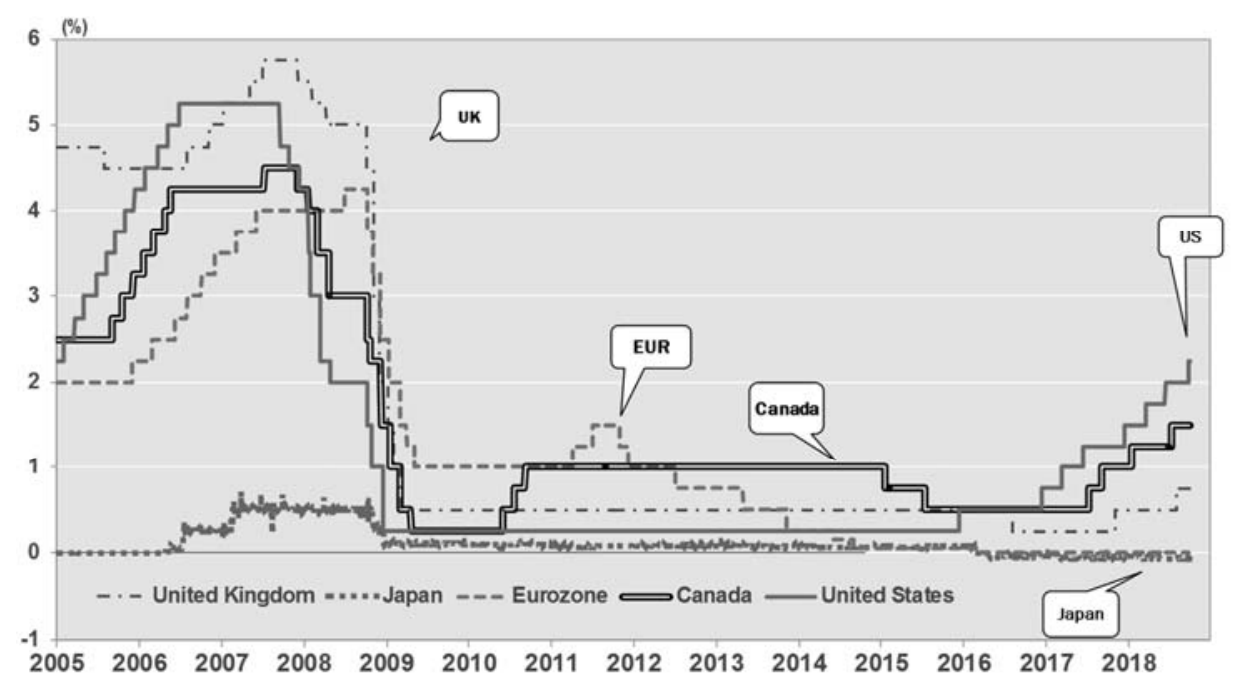

Figure 3. Central bank policy interest rate

Source: Bloomberg Market Data, Last observation: 2 Oct, 2018.

risk that these unconventional policies, which were initially believed to be just a temporary detour from the conventional policy regime, might become the new paradigm, and thereby constitute the new set of conventional policies.

There is a complete consensus that in the United States, following the outbreak of the crisis, the initial monetary policy response by the Federal Reserve has been both essential and successful. Quantitative easing (QE) was appropriate and effective. With the passage of time, however, when the first round of quantitative easing (QE1) did not bring about the full recovery, especially due to the fact that a large share of the burden of policy adjustment fell on the shoulders of the Federal Reserve, another round of QE was adopted - QE2. Monetary policy became overburdened and when the desired recovery did not yet fully materialize, the next round of expansion took place - QE3. In retrospect, each round was productive, but its effectiveness diminished - the law of 'diminishing returns' took hold. Across the Atlantic Ocean, in Europe, the European Central Bank (ECB) also engaged in its own version of QE. The challenges in Europe were more severe, since there are many diverse governments, diverse economic conditions, labor markets that are less flexible, and the banking union is still not in place. A similar challenge characterized the situation across the Pacific Ocean in Japan. The economic strategy in Japan (Abenomics), has been based on the "three arrows" - monetary policy, fiscal policy, and structural policy - but most of the burden fell on the shoulders of the Bank of Japan (BoJ); only one of the three arrows has 


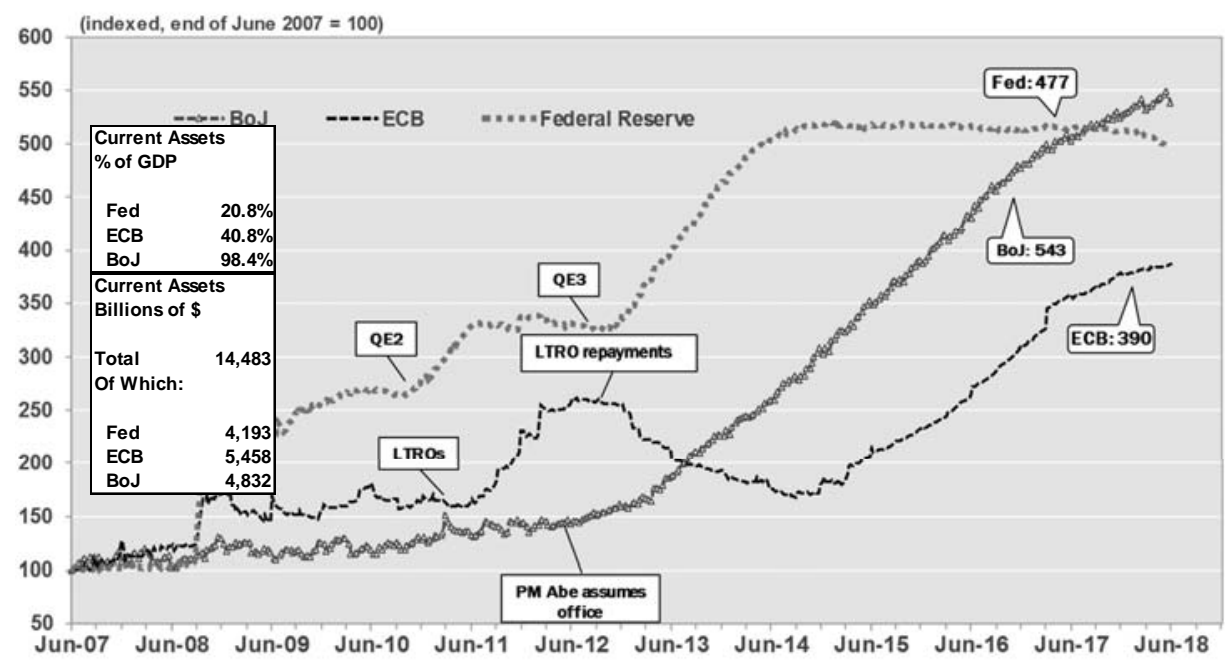

Figure 4. Total assets of key central banks (indexed levels)

Source: Bloomberg; Last observation: Fed: Sept 26,2018; ECB: Sept 21, 2018; BoJ: Sept 20, 2018.

been fully operational. In most of the industrial countries of the world, monetary policy has become overburdened and has become the "only game in town". These developments are illustrated in Figure 4.

\subsection{Normalization}

Everyone recognized that it would be desirable to restore "normalization" and to bring about the conditions that would enable higher central bank interest rates. Much of the debate, however, has been whether the economies are strong enough to warrant the start of normalization. Since the macroeconomic situation differs significantly between the U.S., Europe and Japan, it is clear that normalization should not be initiated simultaneously. In this regard, the United States has best positioned to start the journey of normalization. Economic growth clearly improved (Figure 5), unemployment has declined dramatically (Figure 6), the duration of unemployment has also declined and inflation (net of energy prices) is also on the rise, approaching the two-percent target. While the US normalizes the course of monetary policy by raising short term interest rates and subsequently also reducing gradually the size of the FED's balance sheet, Europe and Japan are not yet ready to normalize their unconventional monetary policies. As a result, there is likely to be a period of time during which monetary policies in the US, 


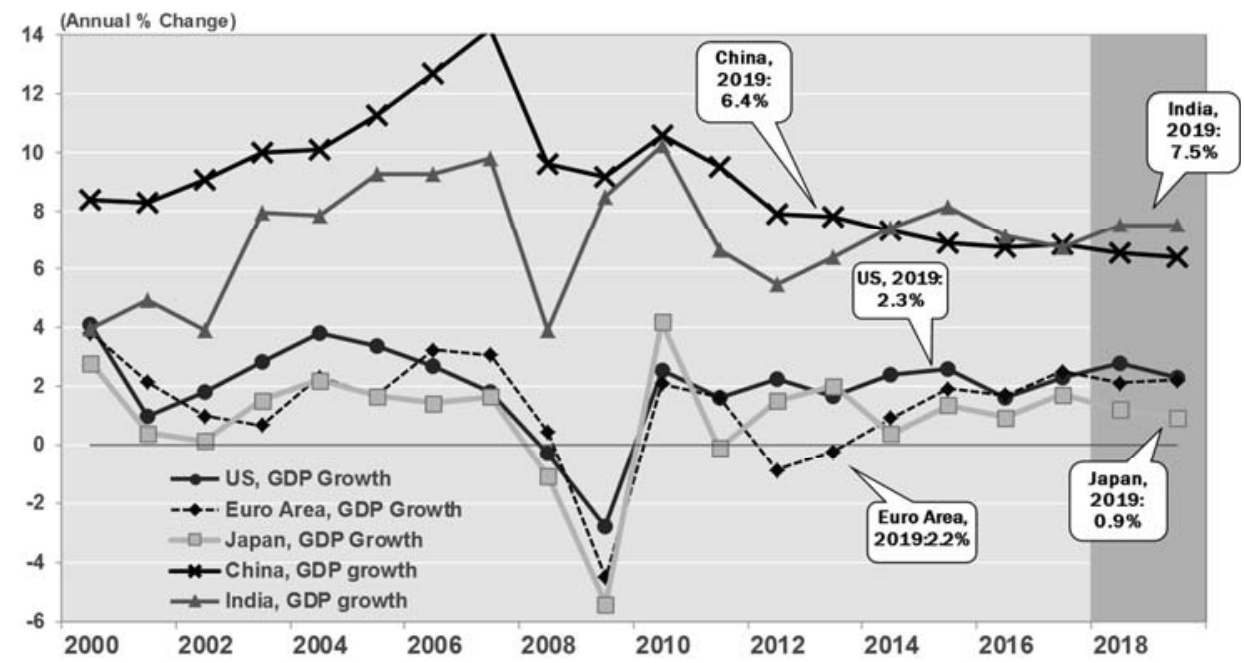

Figure 5. Real GDP growth, select countries

Source: IMF, last update Jul 16 2018, WEO (2018, 2019 are forecasts); For US and Euro area 2018, 2019 are JPM forecasts, last update September 28, 2018.

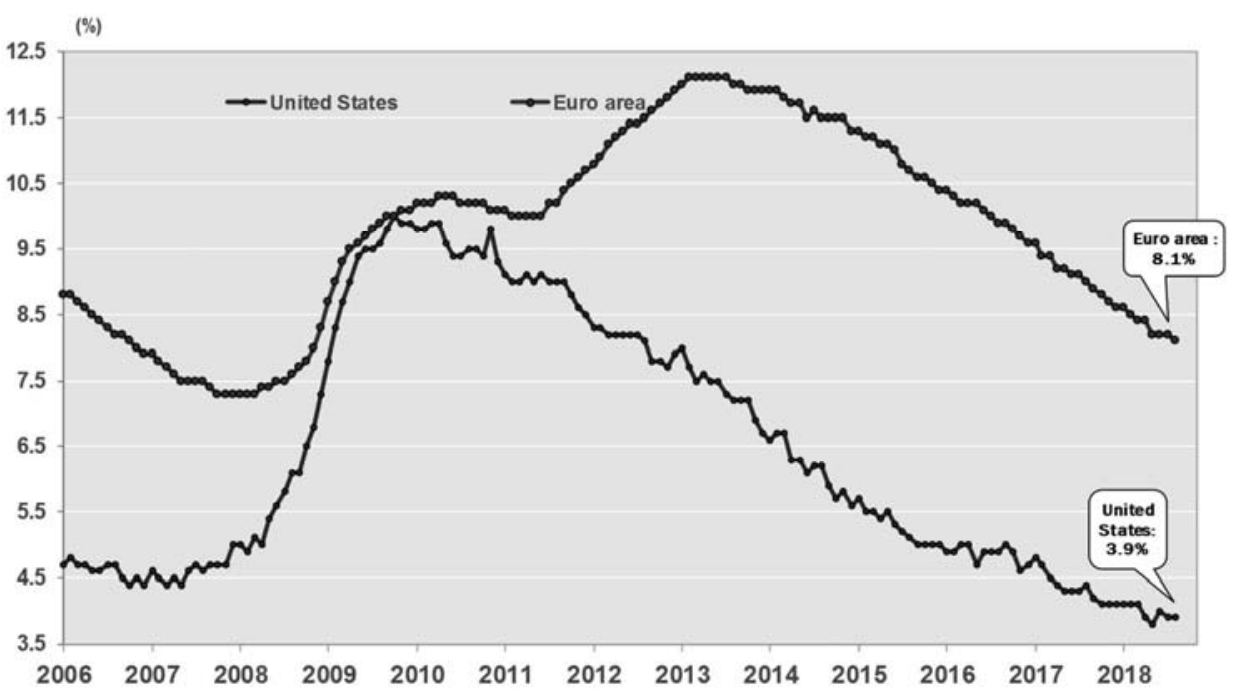

Figure 6. Unemployment rate: US and euro area

Source: Eurostat and BLS; Last observation for Euro area August 2018, for US, August 2018. 
Europe and Japan would differ from each other. These diverging paths of monetary policies are likely to be reflected in corresponding changes in exchange rates whereby the US dollar appreciates relative to the other currencies. Such exchange rate changes are desirable. They reflect a healthy component of the international adjustment mechanism, and should not be resisted. Furthermore, the appreciation of the US dollar relative to the Euro should also shorten the period of time that the ECB requires before it also initiates normalization.

Much of the discussion about normalizing the course of monetary policy have focused on the negative consequences of higher interest rates. An excessive focus on the cost of normalization rather than its benefits increases the risk that such normalization will be initiated too late. In order to restore balance to the discussion regarding normalization of monetary policy, it is important to recognize that maintaining an exceedingly low interest rate and delaying the process of normalization is also costly. It entails economic costs that need to be taken into account. In what follows, I list some elements of such cost:

1. The low-interest rates induce investors to seek alternative ways to generate returns. By chasing after yield, investors end up assuming higher risk, which might be mispriced.

2. The low-interest rates bring about an inflation of stock prices and may generate a financial bubble.

3. Corporations divert their efforts towards stock buy-backs instead of allocating their resources to investment in plant and equipment.

4. The inflated financial markets create a disconnect between the real and the financial sectors of the economy.

5. The low-interest rates encourage excessive leverage and thereby increase the vulnerability of the financial system.

6. The low-interest rates and the flat yield curve result in negative consequences for the financial-services industry. This includes: banks, insurance companies, and pension systems.

7. The transmission of the effects of monetary policy through the economy operates through the financial system; a weakened financial system reduces thereby the effectiveness of monetary policy.

8. The low-interest rates provide an artificial stimulus to interest-sensitive sectors, such as housing. Since this sector is typically a low-productivity sector, it results in an overall reduction in the productivity of the economy.

9. The excessive reliance on monetary policy enables governments to postpone the necessary fiscal and structural measures. The postponement of these measures reduces the flexibility of the economy, and thereby reduces productivity and growth. 
This partial list of the negative consequences of excessively low rates of interest suggest that a delayed normalization is costly and that one should always balance these costs against the cost of normalization. Obviously, most central banks are fully aware of these considerations, but on balance it seems that the public and the political debate of these issues put a greater weight on the arguments highlighting the cost of normalization than on the arguments highlighting the benefits from normalization. If such a bias exists, it is likely that when the process of normalization does take place, it will be implemented too late and might proceed too slowly. An undue delayed normalization may entail significant cost.

\subsection{Inflation targets}

The risk that normalization might be excessively delayed is enhanced by the fact that recently all the major central banks put extraordinary emphasize on achieving their two-percent inflation target. This is true of the Federal Reserve, the Bank of England, the European Central Bank, the Bank of Japan and others. There are many reasons (some of them not under the control of the central bank) as to why, in spite of the extraordinary efforts, the rates of inflation in the industrial world have been very low and have gotten 'stuck' below the two-percent target. If, 'no matter what', interest rates are to be maintained at exceedingly low levels, for as long as the rate of inflation is below two percent, then there is a significant possibility that financial stability might be at risk. The BIS has forcefully voiced this concern and I believe that it would be prudent to pay a significant attention to the concern regarding financial stability.

Inflation targets have proven to be highly successful as a strategy for disinflation in countries with high inflation. In such cases the path of the inflation targets is the compass, which provides credibility and transparency to the multi-year policy goal of achieving a gradual reduction of inflation towards medium-term price stability. For such countries it is less critical if a range of which the mid point is 2.0 percent, or 1.5 percent, or 2.5 percent defines the long- term goal of 'price stability'. This is not, however, the policy challenge faced today by the United States and Europe (as well as by many other industrial countries). These countries have already achieved medium-term price stability; their aim is to preserve it by keeping their inflation rate within the price-stability target range. For these countries it matters a great deal if the mid point of its target range is 2.0 or 1.5 or 2.5 percent.

Setting the inflation target at the rigid level of two percent (or slightly below two, in the case of the ECB) represents an interesting convergence of views among the major central banks. The various statements of the major central banks, 
which are intended to provide the markets with forward guidance, illustrate this convergence (see Appendix).

It is relevant to note, however, that the choice of the two percent target rate is somewhat arbitrary and, although the two-percent target rate has become the consensus target for most of the industrial-countries' central banks, its theoretical foundations can be questioned especially if the two-percent target is set as a rigid quantitative target rather than as the mid-point of a wider target range. In this context it should be emphasized that the "whatever it takes" dictum stated by Mario Draghi (the ECB's President), is not intended to apply to the medium-term inflation target. Specifically, on July 26, 2012, in his breakthrough speech, Mario Draghi stated that: "Within our mandate, the ECB is ready to do whatever it takes to preserve the euro. And believe me, it will be enough". Thus, this justifiably famous statement addresses the challenge of preserving the euro (within the ECB's mandate) rather than sticking blindly with the inflation target.

Recently, there have also been proposals that the Federal Reserve should raise its inflation target above two percent. The logic of the proposal rests on the fact that real interest rates have declined to very low levels and that with the existing two-percent inflation targets, the resultant levels of nominal rates (the sum of the real rate of interest and expected inflation) are too low. Hence, so the argument goes, a higher level of inflation targets would permit higher nominal rates of interest even though the real rates of interest are at historically low levels.

This policy recommendation, however, is subject to several reservations: First, before considering to raise the inflation target, we should have a better understanding as to the reasons for the decline in the real rate of interest. Specifically, among the factors responsible for the low real rates are demographic factors, uncertainty, a lower level of productivity, and the like. Raising the inflation target would imply that the exceedingly low level of the real rate of interest is here to stay; the higher inflation target in fact would validate the low real rate. I believe that this verdict is premature. Some sources of the uncertainty are policy induced and should be removed; furthermore, the low level of productivity should also not be taken as a given, and policy efforts should be directed towards raising productivity. These efforts should typically be affected through the implementation of structural policies that remove distortions and increase the flexibility of the economic system, through improved infrastructure, education, and tax incentives that promote an innovative culture.

In addition to these points of principle, there is a practical issue. Most of the major central banks such as the Fed, the ECB, the Bank of Japan, and the Bank of England, have been struggling for a while to raise their corresponding inflation rates from a near zero levels towards their inflation targets of about two percent per year. What good would it make to raise the inflation target above its 
current level of two percent when the level of actual inflation is stuck below two percent?

Furthermore, there are still many countries especially in emerging economies, which suffer from high inflation. For such countries, the challenge is to lower inflation towards its target. The credibility of the inflation targeting strategy, which is the main strategy adopted by this group of countries, would be seriously eroded by changing the inflation target. If the industrial countries were to raise the inflation target as proposed, it would damage the efforts of the emerging markets who are still struggling to adhere to their inflation targeting strategy in an effort to achieve price stability.

\subsection{Conclusions on central banking}

I conclude this section on central banking and monetary policy by noting that in spite of the changing circumstances and the new challenges faced by policy makers, it is important to maintain the fundamental principles of central banking. The medium term focus on stability, both price stability and financial stability, are and should remain the key objectives of the central bank. In order to achieve these objectives, the central bank must be granted operational independence (autonomy). Furthermore, a strong financial system is fundamental for the maintenance of stability, and such stability is the precondition for the attainment of sustainable growth. In fact, the best way that the central bank can contribute to sustainable growth is through delivering price stability and financial stability. A strong banking system is key for such stability as well as for the effective transmission of monetary policy. High capital ratios, low leverage, and high liquidity, characterize a strong banking system. In order to discharge the central bank's responsibilities, it must have the authority and the tools to bring about a strong financial system. Hence, in most cases it would be desirable that the responsibility for bank supervision rests in the hands of the central bank. Furthermore, the central bank should also be granted the authority and the instruments to secure the smooth operation of the payment system. This is especially the case during financial turmoil.

These objectives represent a very heavy list of tasks and it should be clear that the central banks could not do it alone. There should be a full cooperation from the other branches of government that will secure fiscal responsibility, open trade, structural policies, and the like. Without such cooperation, monetary policy will be overburdened, the central bank will be the only game in town, and economic performance will be below potential. 
Crises are a typical phenomenon of the modern economic and financial systems. The role of policy is to design effective mechanisms for crisis prevention, crisis management, and crisis resolution. Occasionally, the appropriate policy response to a crisis entails a departure from typical norms of policy. These are the occasions that the credibility of the policy strategy plays a critical role in the restoration of stability. For such credibility to be maintained it is important that such departures from the norm be viewed as a temporary detour rather than a permanently new paradigm. The medium term perspective of the conduct of policy provides the compass that ensures that the long-term objectives are achieved.

\section{GLOBALIZATION, CHINA, TRADE AND PROTECTIONISM}

The global financial crisis has also brought about skepticism about the benefits from globalization, a revival of calls for protectionism and a growing prevalence of populism in the economic and the political spheres. These sentiments have also been stimulated by, and reflected in, the relations with, and the attitude towards, China. The growing weight of China in the global economy illustrates the benefits from trade, the dangers from protectionism, and the role of globalization. Over the past 20 years China's economic growth has been spectacular, averaging about 10 percent per year. More recently, its annual growth rate has moderated to a more sustainable rate of about 6.5 percent. This exceptional performance of the Chinese economy should be recognized as being a megatrend rather than an episodic temporary performance. China is still saving about 45 percent of its income. Whatever misallocation China may have, it is bound to continue to be an accumulator of assets in the global economy. The growing role of China is also reflected in its relative share in world output. To illustrate, in 1990, China produced only about 4 percent of world output; in contrast, in 2018, China produced about one fifth of world output (Figures $7 a, 7 b$ ).

China's opening to international trade has been a critical factor underlying its exceptional economic performance. It also brought about the rapid alleviation of poverty of tens of millions of Chinese citizens.

In addition to its dominant position in world output, China has also become an indispensable player in world trade, thereby reflecting the shift in the economic center of gravity towards Asia. During 2018 the volume of trade between China and the rest of Asia has been about twice as large as the corresponding volume of trade between China and the US plus Europe taken together. Furthermore, China has become the most important trading partners of most of the major industrial countries in the world. For example, during 2018, as illustrated in Figures $8 a$ and $8 b$, approximately one-quarter of US and European exports are shipped to China. 


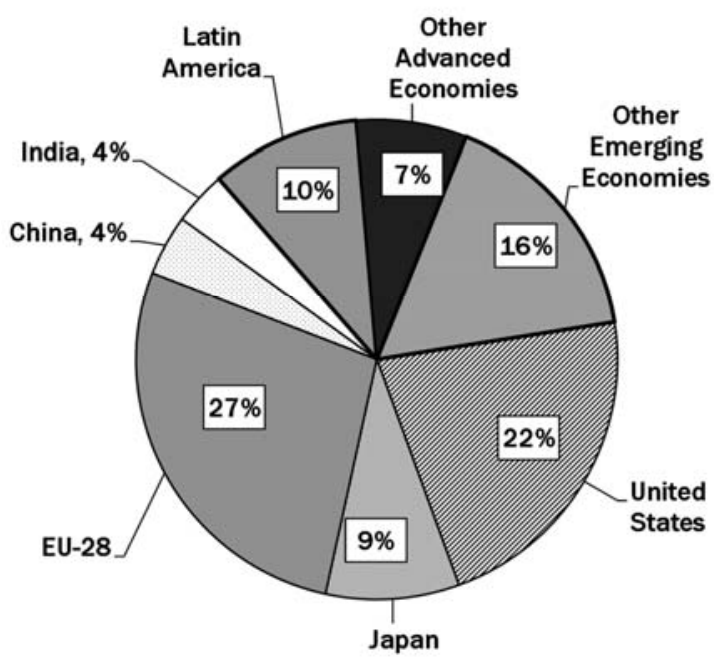

Figure 7a. Global GDP shares -1990

Source: IMF, WEO Database, last update Apr. 17, 2018, WEO.

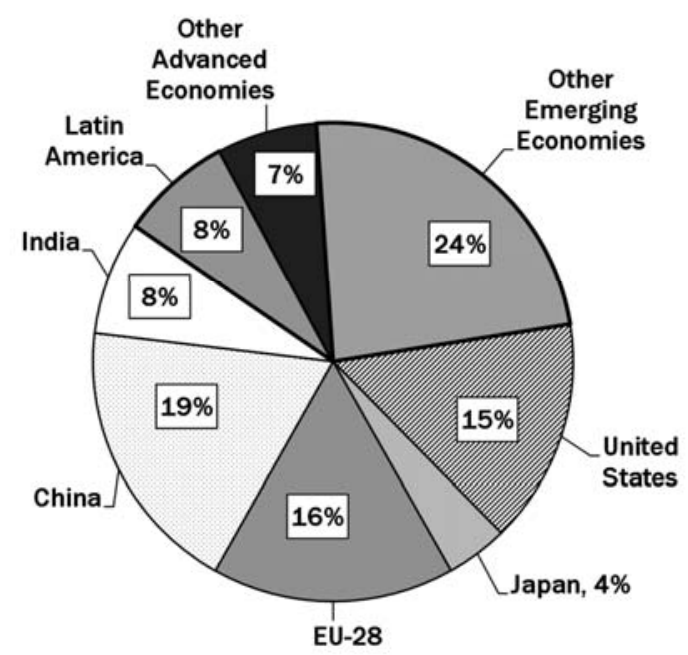

Figure 7b. Global GDP shares -2018

Source: IMF Forecast, WEO Database, last update Apr. 17, 2018, WEO. 


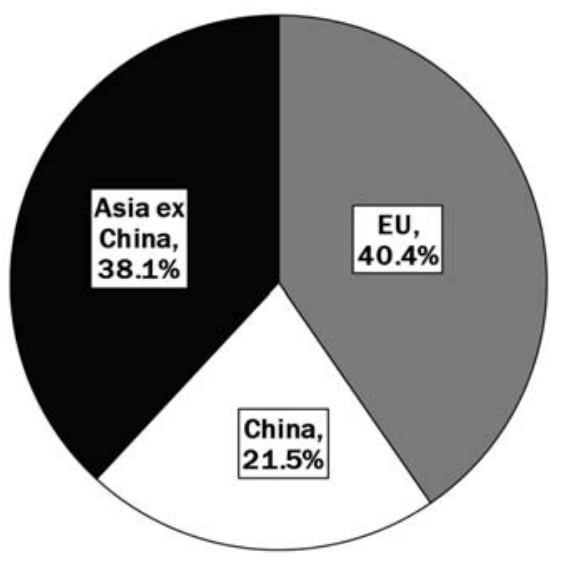

Figure 8a. US exports by destination - 2018

Source: US Department of Commerce, Last observation: Jul 2018.

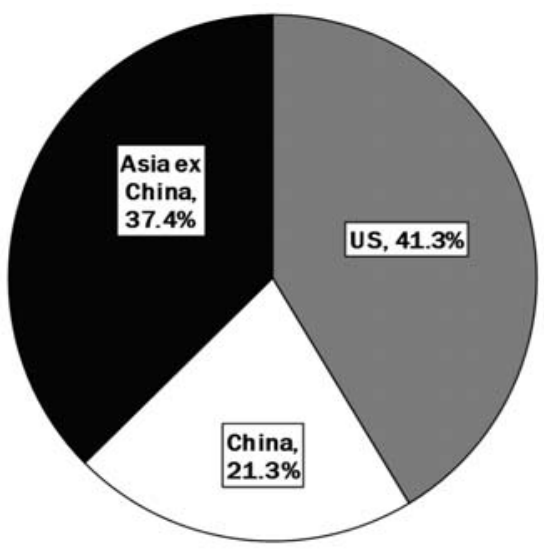

Figure 8b. European exports by destination - 2018

Source: Eurostat, Last observation: Jul 2018.

These facts imply that the degree of interdependence within the world economy is very high. As a result, a protectionist induced disruption to the interrelation between China and the rest of the world would be extremely costly.

An illustration of the strong relationship between international trade and economic growth is provided by reference to Figure 9, which depicts the evolution of the volume of world trade during the past 30 years. It shows that except for 2009 the volume of world trade has expanded in each and every year. During 2009 the worse year of the global financial crisis - the volume of world trade shrunk 


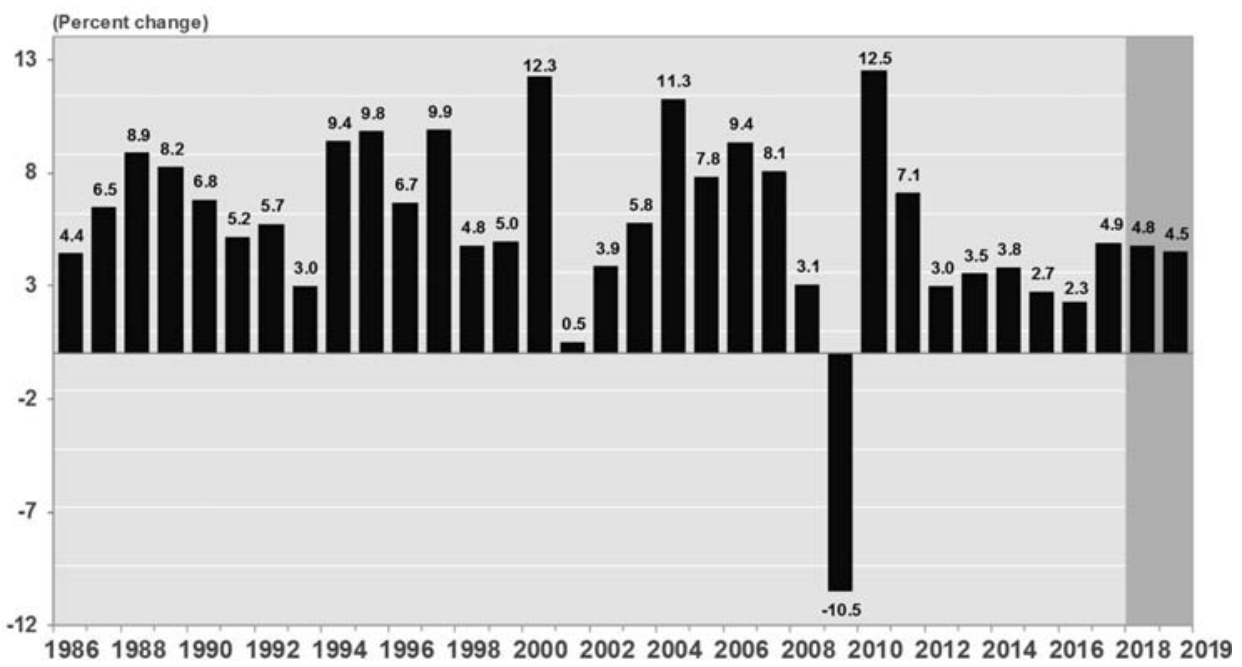

Figure 9. World trade volume

Source: IMF, average annual growth rates, last update Jul 16, 2018, WEO (2018, 2019 forecast).

by 10.5 percent. As shown in Figures 1 and 2, 2009 was also the year characterized by the worse economic performance of the world economy: global GDP was stagnant while, at the same time, the level of GDP of the industrial countries shrunk by 3.4 percent.

Protectionism would reverse the great benefits that have been brought about through international trade; the damage to the interdependent world economy would be immense.

One of the main lessons from the recent global financial crisis is the importance of ensuring a robust financial system with a special focus on the health of the banking system. This is one of the major challenges that still remains and that must be addressed with great urgency by the Chinese authorities. In this regard it is also important that the activities of the Chinese shadow banking be illuminated, taken out of the shadow, and become fully transparent. Furthermore, it is important that the non-performing loans that are still prevalent on the balance sheets of the Chinese financial institutions are handled properly.

Notwithstanding these considerations, however, I am still optimistic about the role that China plays and can play in the global economic system. The recent initiative of China in launching the Asian Infrastructure Investment Bank (AIIB) is a positive and encouraging development. It is encouraging that most of the major countries have joined this new multilateral bank, and one can only hope that the United States and Japan will also join this initiative before too long. Generally 
speaking, China should be granted its appropriate place in the formal international architecture and its quota shares in the multilateral organizations should be commensurate with its economic size.

In view of these developments the recent popularity of protectionism is worrisome. It needs to be confronted with massive educational efforts highlighting the key issues and the ways to address them. In fact, most people who support protectionism would clearly prefer not to give up the gains from trade. They justify their protectionist stance by noting that, in many cases, opening the economy to international trade may inflict hardship on some segments of the population. In this regard it is important to emphasize that the appropriate way to address this challenge is through fiscal measures. Such measures include trade-adjustment assistance, retraining programs, and appropriately budgeted safety nets designed to support the weakest segments of society. Generally, hardships that are associated with the opening to international trade do not arise directly from trade but rather from the failure of governments to enact the appropriate fiscal measures. It will be tragic to forego the gains from trade, just because governments are unable or unwilling to implement the appropriate fiscal policy measures that simultaneously secure the gains from trade, while at the same time, reduce the hardship that may accompany trade.

\section{POPULISM}

In addition to the dangerous popularity of protectionism, the global financial crisis has also resulted in the emergence of populist sentiments that are manifested in the economic sphere as well as in the political sphere. In the economic sphere, trend changes in the distribution of income have been a source for the growth of populism. Since the 1980s, in the industrial countries, the relative share of labor in GDP has been on the decline. The decline of the share of labor has been correlated with the rise in income inequality. Those at the higher end of the income distribution are also the owners of capital, so when the relative share of capital in GDP rises, it is associated with a rise in income inequality - but that, again, has little to do with trade or with technological advance. This implies that we need to focus on the question, why the relative share of labor has declined, rather than adopt a populist stance.

In the political sphere one of the reasons for the growth of populism has been the dramatic decline in the levels of trust. An increasing number of people feel that the politicians and the political system have failed to serve them well. A growing number of people feel that they have been left behind and, for the first time since many years, a growing number of families doubt that their children will be better off than they are. 
Furthermore, people have lost their trust in what they read or listen to in the media. Everyone has his own "truth". The truth that people believe in is typically the one that is shared by the group of people that they are associated with and, typically, people associate themselves with others who hold similar beliefs and values. This is the way in which groups are formed in the social media world. Individuals who belong to a WhatsApp group or WeChat group or other groups within Facebook typically share the same beliefs and values. By talking to each other they define their collective "truth". At the very same time, the same happens in other groups who define their collective truth. Under these circumstances, it is typical that political election results are not easy to forecast, since every group believes that everyone thinks like them because these are the views that they encounter within their own group. It is no wonder that most of the recent forecasting of political election results failed dramatically.

In addition to the diminished trust in politicians and the media, there is also a diminished trust in experts. One of the unfortunate consequences of the global financial crisis has been the perception that "experts have failed". As a result, being an expert is not viewed as an advantage but rather as a disadvantage. Likewise, having experienced persons in leadership positions is viewed as a liability rather than an asset. This has resulted in a growing popularity and prominence of inexperienced political candidates and in the elections of "outsiders". In the complex world of today, this phenomenon of the rise to prominence of outsiders and inexperienced leaders should be viewed with concern, especially as it has been accompanied by populism and anti-trade sentiments of protectionism.

\section{CONCLUSION}

The recent global financial crisis has resulted in a new creative set of economic policies. Both fiscal and monetary policies have departed from their conventional course. Faced by a colossal crisis, budget deficits were raised to levels that normally would have been viewed as excessive, especially in view of the already high levels of leverage, which prevailed in the major industrialized countries. At the same time monetary policies responded to the crisis by adopting an extremely expansionary stance which, under normal circumstances, would have been regarded as excessive. Central banks' interest rates were reduced to zero (and below) whereas real interest rates became negative. The justification for the unconventional course of the policy response was based on the argument that "unusual challenges must be met by unusual policies". Furthermore, the implicit assumption was that the departure from the norms of macroeconomic policies would be temporary, and that following a relatively short detour into the uncon- 
ventional territory, the course of macroeconomic policies would return to its conventional path. In practice this detour has lasted longer than expected. Now that the process of normalization has started in the United States and is likely to be followed (albeit in some delay) in Europe, it would be important that policy makers emphasize that the unconventional set of economic policies were just a detour from the longstanding convention rather than representing a new paradigm. This experience should be recorded in history as reflecting a period during which new and important policy chapters were drafted. These chapters should be added to the corpus of knowledge of macroeconomic theory and policy. The new chapters contain important lessons that should definitely not be forgotten once the crisis is over. They should be added to, but not replace, the old textbooks. These old textbooks should definitely not be thrown away as they summarize lessons from the experience from many decades past.

The occasion of the $10^{\text {th }}$ anniversary of the crisis provides an excellent opportunity to look back, reflect, and appreciate the critical role that central banks can play in an economy that undergoes fundamental changes. It also provides an opportunity to appreciate the benefits from globalization, from keeping open markets, and from maintaining free international trade. At the same time, this reflection should lead us to recognize the dangers and damages that result from inward looking protectionism and from populism. Let's remember: the fundamental principles that over the past several decades have provided the basis for the conventional set of macroeconomic policies are still highly relevant and robust; they stood the test of time and space, and are likely to serve us well also in the future. 


\section{APPENDIX}

Below are samples of recent statements by the Federal Reserve (1), the Bank of England (2), the ECB (3) and the Bank of Japan (4). Each one of these statements refers to the two-percent inflation target.

1. "Consistent with its statutory mandate, the Committee seeks to foster maximum employment and price stability. The Committee expects that further gradual increases in the target range for the federal funds rate will be consistent with sustained expansion of economic activity, strong labor market conditions, and inflation near the Committee's symmetric 2 percent objective over the medium term...In determining the timing and size of future adjustments to the target range for the federal funds rate, the Committee will assess realized and expected economic conditions relative to its maximum employment objective and its symmetric 2 percent inflation objective.” FOMC Statement, September26, 2018.

2. “The Bank of England's Monetary Policy Committee (MPC) sets monetary policy to meet the $2 \%$ inflation target, and in a way that helps to sustain growth and employment....The Committee judges that, were the economy to continue to develop broadly in line with the August Inflation Report projections, an ongoing tightening of monetary policy over the forecast period would be appropriate to return inflation sustainably to the $2 \%$ target at a conventional horizon.” Minutes of the MPC Meeting September 13, 2018.

3. "We continue to expect them [rates] to remain at their present levels at least through the summer of 2019, and in any case for as long as necessary to ensure the continued sustained convergence of inflation to levels that are below, but close to, $2 \%$ over the medium term...In any event, the Governing Council stands ready to adjust all of its instruments as appropriate to ensure that inflation continues to move towards the Governing Council's inflation aim in a sustained manner." ECB President Mario Draghi, Introductory Statement, September 13, 2018.

4. “The Bank will continue with 'QQE with Yield Curve Control,' aiming to achieve the price stability target of 2 percent, as long as it is necessary for maintaining that target in a stable manner...It will examine the risks considered most relevant to the conduct of monetary policy and make policy adjustments as appropriate, taking account of developments in economic activity and prices as well as financial conditions, with a view to maintaining the momentum toward achieving the price stability target.” Statement of Monetary Policy, September 19, 2018. 